\title{
Stem vacuole-targetted sucrose isomerase enhances sugar content in sorghum
}

\author{
Guoquan Liu ${ }^{1 *} \mathbb{D}$, Yan Zhang ${ }^{1}$, Hao Gong ${ }^{1}$, Shan Li ${ }^{1}$, Yunrong Pan ${ }^{2}$, Christopher Davis ${ }^{2}$, Hai-Chun Jing ${ }^{3}$, \\ Luguang $\mathrm{Wu}^{2}$ and lan D. Godwin ${ }^{1}$
}

\begin{abstract}
Background: Sugar content is critically important in determining sugar crop productivity. However, improvement in sugar content has been stagnant among sugar crops for decades. Sorghum, especially sweet sorghum with high biomass, shown great potential for biofuel, has lower sugar content than sugarcane. To enhance sugar content, the sucrose isomerase (SI) gene, driven by stem-specific promoters ( $A 2$ or $L S G$ ) with a vacuole-targetted signal peptide, was transformed into the sorghum inbred line $(T \times 430)$.

Results: The study demonstrated that transgenic lines of grain sorghum, containing 50-60\% isomaltulose, accumulated up to eightfold $(1000 \mathrm{mM})$ more total sugar than the control $\mathrm{T} \times 430 \mathrm{did}(118 \mathrm{mM})$ in stalks of $\mathrm{T}_{0}$ generation. Subsequently, the elite engineered lines (A5, and LSG9) were crossed with sweet sorghum (Rio, and R9188). Total sugar contents (over $750 \mathrm{mM}$ ), were notably higher in $F_{1}$, and $F_{2}$ progenies than the control Rio $(480 \mathrm{mM})$. The sugar contents of the engineered lines (over $750 \mathrm{mM}$ ), including $T_{0}, T_{1}, F_{1}$, and $F_{2}$, are surprisingly higher than that of the field-grown sugarcane (normal range 600-700 mmol/L). Additionally, analysis of physiological characterization demonstrated that the superior progenies had notably higher rates of photosynthesis, sucrose transportation, and sink strength than the controls.

Conclusions: The genetic engineering approach has dramatically enhanced total sugar content in grain sorghum $\left(T_{0}\right.$, and $\left.T_{1}\right)$ and hybrid sorghum $\left(F_{1}\right.$, and $\left.F_{2}\right)$, demonstrating that sorghum can accumulate as high or higher sugar content than sugarcane. This research illustrates that the S/ gene has enormous potential on improvement of sugar content in sorghum, particularly in hybirds and sweet sorghum. The substantial increase on sugar content would lead to significant financial benefits for industrial utilization. This study could have a substantial impact on renewable bioenergy. More importantly, our results demonstrated that the phenotype of high sugar content is inheritable and shed light on improvement for other sugar crops.
\end{abstract}

Keywords: Isomaltulose, Sorghum, Sucrose isomerase, Sugar content, Renewable energy, Photosynthesis, Genetic engineering, Sugarcane

\section{Background}

Sugar yield, largely impacted by biomass and sugar content, is a key determinant of economic sustainability for sugar crops. In recent decades, improvement on sugar

\footnotetext{
*Correspondence: g.liu2@uq.edu.au

${ }^{1}$ Centre for Crop Science, Queensland Alliance for Agriculture and Food Innovation, The University of Queensland, Brisbane 4072, Queensland, Australia

Full list of author information is available at the end of the article
}

yield has been achieved almost entirely by increasing biomass [1-3], despite the higher commercial value and higher heritability of sugar content [4]. Recent studies on manipulation of plant genes, which are involved in sugar metabolism, have been unsuccessful for increasing sugar content in sugar crops [5-7]. There is significant pathway redundancy in elite cultivars to buffer against increases on sucrose levels by manipulating a single gene [8]. Multiple mechanisms appear to contribute to the upper 
limit of sugar concentration, including regulation in signal transduction from specific (e.g., sucrose) or broad (e.g., osmotic) sensors, thermodynamic limitations (e.g., leakage of sucrose through storage compartment membranes), or energetic limitations (e.g., continuous 'futile' cycle of sucrose cleavage and synthesis within the storage pool) [9-12].

Among sugar crops, sugarcane accounts for almost 80\% of global sugar production. Sweet sorghum has displayed huge potential to be multiple sources of energy, food and animal feed and could be a substitute for sugarcane to produce biofuel $[13,14]$. It grows quickly in adverse stress conditions of marginal lands in tropical, subtropical and temperate zones. It is a $\mathrm{C}_{4}$, drought tolerant, high biomass, and high water use efficiency crop that produces stalks up to five meters tall, accumulating sucrose ( $\alpha$-D-glucopyranosyl-1,2-D-fructofuranose). However, current sweet sorghum varieties, producing comparatively low sugar content (around $500 \mathrm{mmol} / \mathrm{L}$ ), urgently require plant breeders to improve sugar accumulation in stalks for biofuel [13].

Sucrose can be converted into isomaltulose ( $\alpha-D$ glucopyranosyl-1,6-D-fructofuranose) by certain bacteria [15]. Unlike sucrose, isomaltulose cannot be digested by invertases [16] nor be metabolized by majority microbes, including the predominant oral microflora, presenting benefit in many foods as an acariogenic sweetener [17]. Meanwhile, isomaltulose can be digested by humans with the same glucose/fructose as primary products and have the same final energy value as sucrose. Interestingly, the first step of digestion involves an intestinal disaccharidase rather than salivary invertase, which slows down the isomaltulose digestion. The slow process of digestion results in less fluctuation of glucose and insulin concentration in blood [18]. Therefore, isomaltulose has a growing demand as a stable, slowly digestible, acariogenic, nonhygroscopic sugar in the modern world [18-20]. Futhermore, isomaltulose has an accessible carbonyl group, which makes it attractive as a renewable starting material for manufacture [21]. The application is currently limited due to the high cost of isomaltulose production through fermentation [22, 23].

Isomaltulose can be produced through expression of the sucrose isomerase $(S I)$ gene in plants [24]. Isomaltulose, compared to sucrose, is very slowly metabolized and cannot be transported in plants [25], hence the site of isomaltulose production becomes a storage. Exogenous application of isomaltulose triggers some plant sugar sensing mechanisms and changes gene expression profiles differently from sucrose $[25,26]$. Previously, it was demonstrated that the efficient conversion of sucrose into the non-metabolized isomer (palatinose) is disruptive or lethal for plant development [27]. The tuber-specific expression of the apoplasm-targeted SI allowed the partial conversion of sucrose to isomaltulose in potato, but the total non-structural carbohydrate content was decreased [28, 29]. Significant progress has been made in last two decades. Recent reports have indicated that the N-terminal pro-peptide (NTPP) fragment from sweet potato sporamin can deliver various proteins to the sugarcane vacuole, but low $\mathrm{pH}$ and high protease activity make the vacuole environment hostile [30]. With the availability of strong stem-specific promoters, a highly efficient SI gene, and silencing motifs, high concentration of isomaltulose (up to $483 \mathrm{mM}$ or $81 \%$ of total sugars) has been successfully achieved in sugarcane [15, 24, 31]. To our best knowledge, similar investigations have not been reported in other biomass species yet.

In the storage parenchyma cells of mature stems of sweet sorghum, the sugar storage vacuole occupies about $90 \%$ of the symplast and $80 \%$ of the total tissue space. The vacuole stores a correspondingly large proportion of sucrose, which can accumulate up to $500 \mathrm{mM}$ in stem juice. Our objective was to improve sugar content by targeting stem vacuole with the $S I$ gene. We hypothesized that high isomaltulose concentration could be accumulated in stalks of engineered lines and lead to high total sugar content in sorghum, especially sweet sorghum. Considering the existing transformation system on grain sorghum and the recalcitrance on sweet sorghum transformation, we strategically avoid transforming sweet sorghum directly in this project [32, 33]. However, investigation on grain sorghum and hybrids (sweet $\times$ grain sorghum) could provide insightful information on sugar accumulation in commercial hybrids and sweet sorghum.

\section{Results}

\section{Isomaltulose was efficiently accumulated in $\mathrm{T}_{0}$ transgenic lines}

Twenty independent transgenic lines were demonstrated to contain the sucrose isomerase (SI) gene using the polymerase chain reaction (PCR) analysis. Among these lines, 16 displayed detectable isomaltulose levels by highperformance liquid chromatography (HPLC) in stalks (Fig. 1a). Up to $446 \mathrm{mM}$ isomaltulose was accumulated in stalk juice, which was fourfold higher than the total sugar content of the untransformed $\mathrm{T} \times 430$. The isomaltulose concentrations were substantially variable among lines (Fig. 1b). Similar patterns were observed in two transgenic populations driven by different promoters of $A 1$ or LSG2 (Fig. 1b).

Because the UQ68J SI gene is highly specific for producing isomaltulose [24], trehalulose concentrations were generally below $5 \%$ of the isomaltulose concentrations in the corresponding internodes (Additional file 1: Table S1). The majority of transgenic lines were 

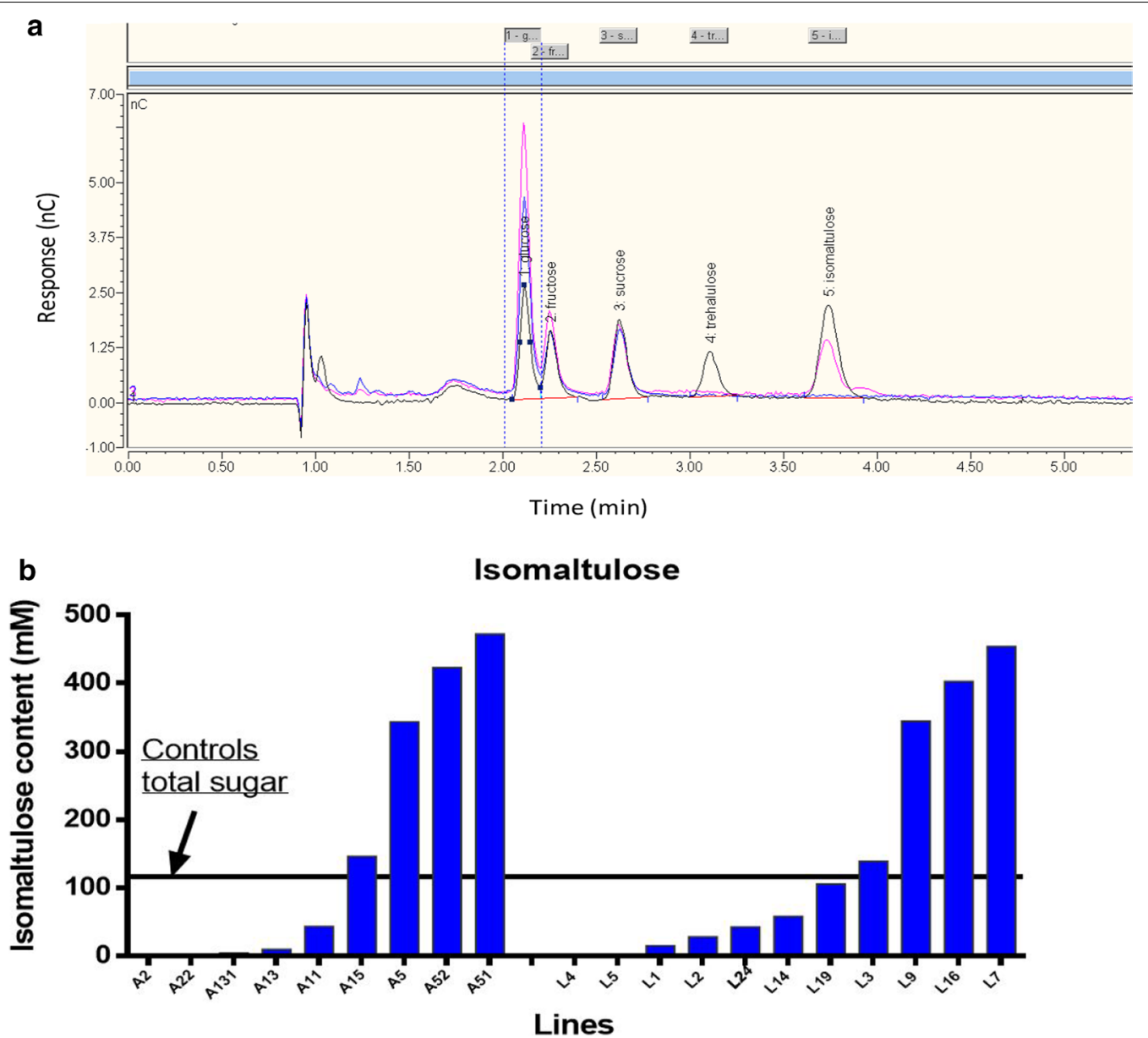

Fig. 1 Screening transgenic $T \times 430$ sorghum lines for the presence of isomaltulose (IM) in stem juice. a High-performance liquid chromatography (HPLC) profiles. Black curve: Standard solutions contained glucose, fructose, sucrose, trehalulose and IM; Pink curve: Diluted (16,000x) juice from transgenic sorghum stalk internode 4 showing isomaltulose (last peak \#5) was accumulated beyond glucose, fructose and sucrose; Blue curve: Diluted $(16,000 x)$ juice from a parent control sorghum stalk showing no isomaltulose accumulated. $\mathbf{b}$ isomaltulose concentrations in juice from the internode 4 of the transgenic lines. The line's label starts with A driven by A1 promoter and with L driven by LSG2 promoter. The plants were the first vegetative generation from tissue culture with around 7 internodes when sampled 20-day post-anthesis. A horizontal line was drawn on the highest total sugar content (sucrose equivalent) among the five $T \times 430$ plants (Controls)

morphologically similar and equivalent to the untransformed control $\mathrm{T} \times 430$ in the glasshouse (Additional file 1: Fig. S1). Transgenic plants flowered at a similar time as the control $\mathrm{T} \times 430$ (Additional file 1: Fig. S1).

The roots and leaves were tested from all the transgenic lines, isomaltulose concentrations were below $5 \mathrm{mM}$ in roots. Isomaltulose concentration increased with age in leaves to a maximum of about $20 \mathrm{mM}$, which is consistent with the expression patterns for the 'stem-dominant' promoters [34, 35]. However, SI enzyme activity could not be detected from cell extracts of transgenic roots or leaves. The negative effect on sorghum growth was not observed due to the small amount of isomaltulose accumulation in roots and leafs (Additional file 1: Fig. S1). Despite substantial isomaltulose accumulation in stalks,
SI enzyme activity was below the detection threshold in cell extracts, indicating a short half-life of this protein after delivery into the acidic/proteolytic sucrose storage vacuoles.

\section{Total sugar content was greatly enhanced in $\mathrm{T}_{0}$ transgenic lines}

The total sugar content has been notably increased in 20 $\mathrm{T}_{0}$ transgenic lines compared to the wild-type control except two lines (L2, and L24), regardless of which promoter used (A1 or LSG2) (Fig. 2). The total sugar contents in internode number 4 of most lines were in a range of 600 to $1,000 \mathrm{mM}$, which was equivalent to five to eight folds of the control (Additional file 1: Table S1). These concentrations were comparable or even higher than that 


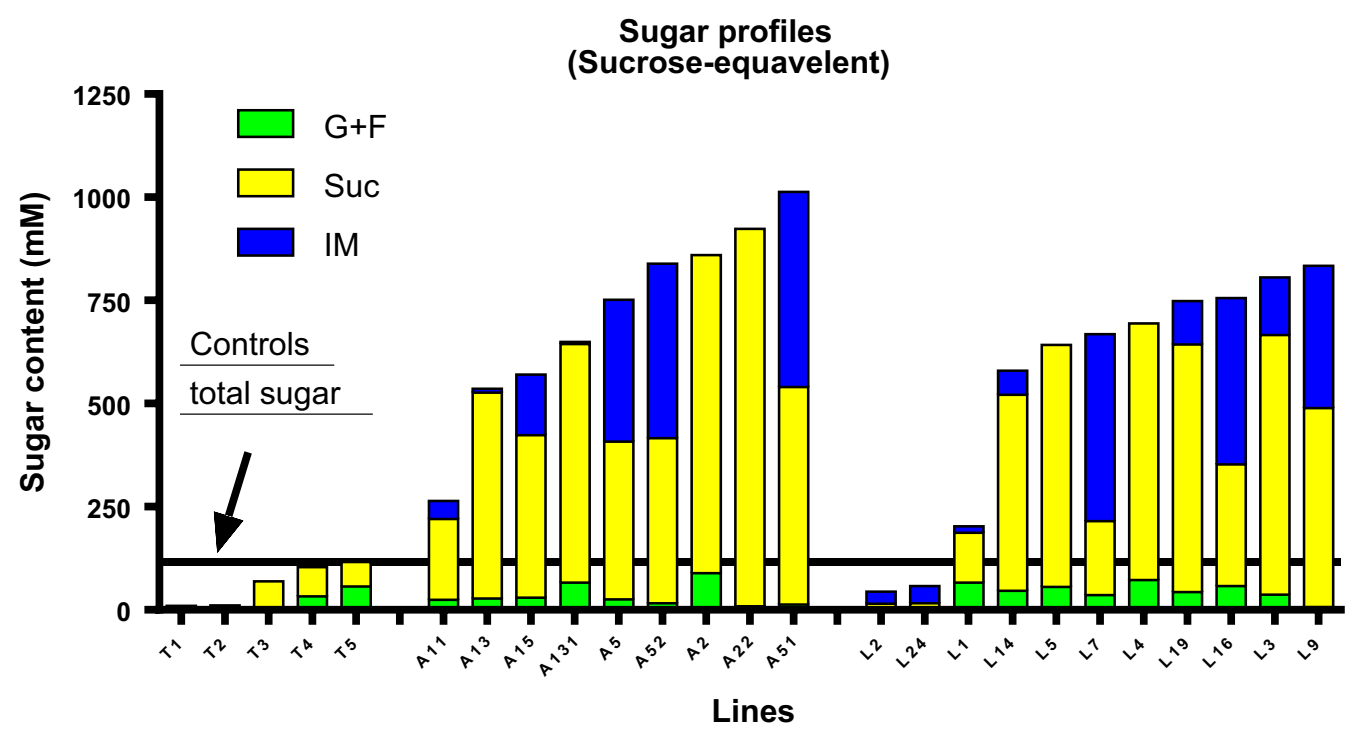

Fig. 2 Total sugar profile of the internode 4 in controls $T \times 430$ and transgenic lines. A horizontal line was drawn on the highest sugar content of the control T×430. G + F: $1 \frac{1}{2}$ (Glucose plus fructose); Suc Sucrose, IM Isomaltulose. T1 to T5: five untransformed T×430 samples; The line's label starts with A driven by $A 1$ promoter and with L driven by LSG2 promoter

of the field-grown sugarcane (normally 600-700 mM). The predominant components of sugar were sucrose and isomaltulose in transgenic lines; meanwhile, their glucose and fructose contents were similar to the parent (Fig. 2). Unexpectedly, some transgenic lines such as L4 and A2 had no detectable isomaltulose but sucrose contents were enhanced fivefold to eightfold when compared to the control $\mathrm{T} \times 430$ (Fig. 2), regardless of the promoter used.

\section{High sugar contents were accumulated across internodes of elite transgenic stalks}

Three transgenic lines, designated A2, A5 (both driven by $A 1$ promoter) and L9 (driven by LSG2 promoter), with high-sugar content were selected for further characterization on sugar profiles in developmental stages. Lines A5 and L9 accumulated high levels of isomaltulose up to $691 \mathrm{mM}$ in juice from mature internodes (Fig. 3c, d). Compared to the control $\mathrm{T} \times 430$, the transgenic lines with high yields of isomaltulose did not show commensurable reduction but enhanced sucrose content in most internodes (Fig. 2). Surprisingly, isomaltulose could not be detected in any A2 tissues including all internodes of the stalks, but sucrose content accumulated eightfold higher than the level in the control $\mathrm{T} \times 430$ (Fig. 3b).

Further investigation on $\mathrm{T}_{1}$ progenies of $\mathrm{A} 2$, A5, and $\mathrm{L} 9$ has been performed and focused on heritability of high sugar content. Up to twelve samples of each progeny have been analyzed. $T_{1}$ progenies of $L 9$ outperformed the counterparts of A2, and A5 in terms of high heritability. Because no isomaltulose was detected in A2, the phenotype of high sugar content did not transmit to the next generation. $\mathrm{T}_{1}$ progenies of A5 accumulated up to $367 \mathrm{mM}$ isomaltulose and up to $550 \mathrm{mM}$ total sugar content, those sugar contents in $\mathrm{T}_{1}$ progenies were not as high as sugar contents in $\mathrm{T}_{0}$ generation. The results of $\mathrm{L} 9$ $\mathrm{T}_{1}$ progeny samples were very promising and displayed high heritability of high sugar content (up to $896 \mathrm{mM}$ in stalk). Positive samples have accumulated much higher sugar content than null-segregants (nil-samples) and the wild-type controls (Additional file 1: Fig. S4).

\section{Real-time PCR was performed on A5, L2, and L9 $\mathrm{T}_{1}$ generation}

Quantitative real-time PCR was deployed to determine the $S I$ gene expression in different transgenic lines. The elite transgenic lines, accumulating high isomaltulose, and high total sugar, A5 and L9 were selected. Line L2, with poor isomaltulose accumulation, was chosen for comparison. Non-transgenic $\mathrm{T} \times 430$ was used as the wild-type control. $\mathrm{T}_{1}$ Positive progenies of A5, L2, and L9 were identified by PCR screening of the $S I$ gene (Additional file 1: Fig. S5). The RT-PCR results revealed that A5 and L9 displayed a relatively high levels of SI gene expression, which are in agreement with their high levels of isomaltulose accumulation. L2 showed comparatively low level of $S I$ gene expression, which aligned with poor isomaltulose accumulation. As expected, no SI gene expression was detected in stalks of the wild-type $\mathrm{T} \times 430$ (Fig. 4). 

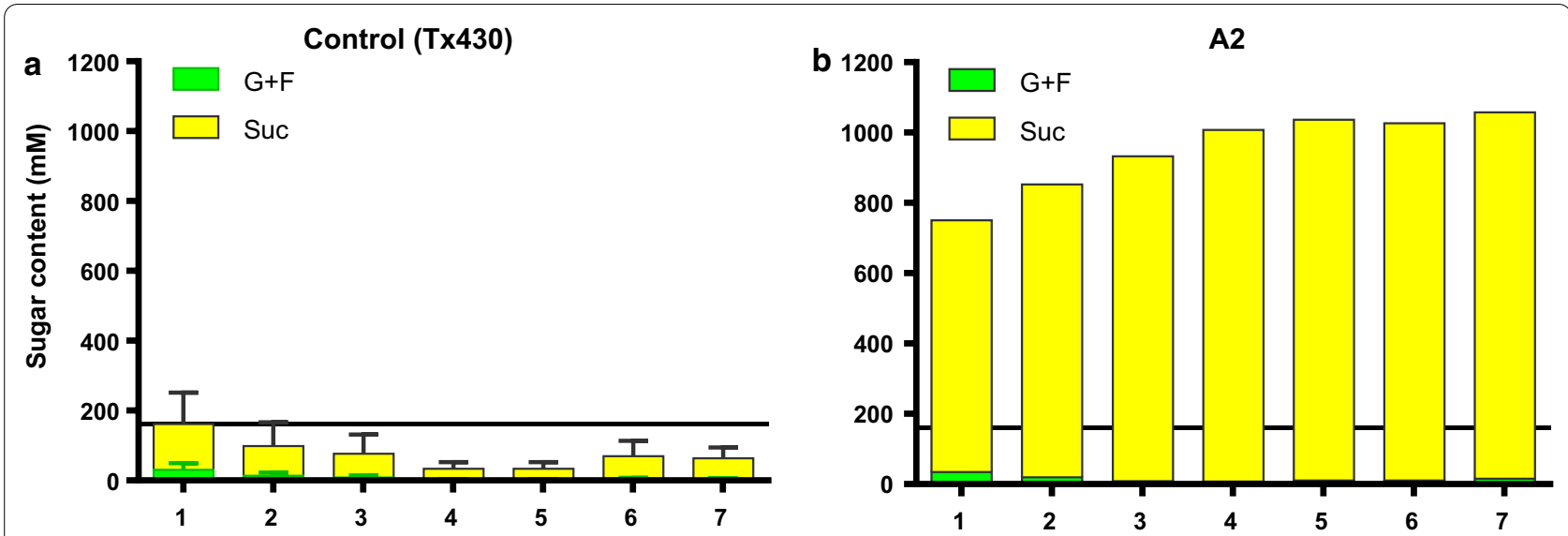

A5
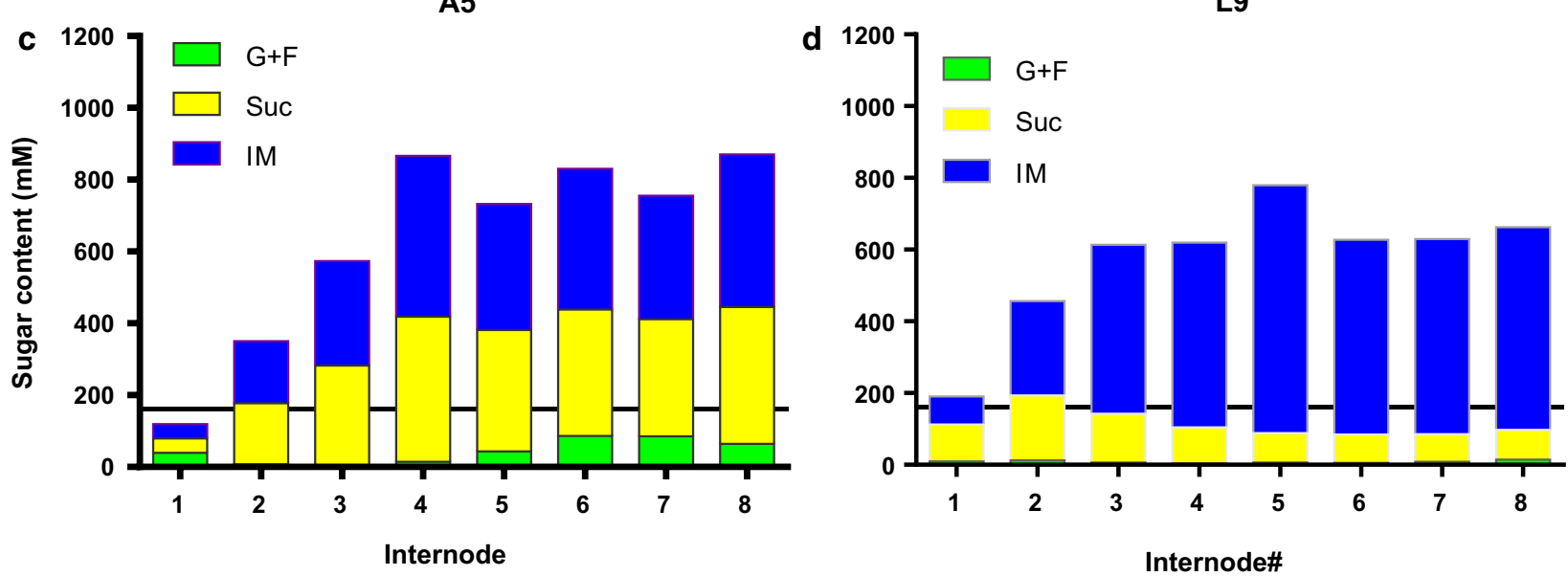

Fig. 3 Sugar profile of internodes in controls $T \times 430$ and transgenic lines. The plants were sampled 20-day post-anthesis with 7-8 internodes. G+F: $1 / 2$ (Glucose plus fructose); Suc: Sucrose; IM: Isomaltulose. Results from the Tx 430 controls are means of five replicates, with standard errors. A horizontal line on each panel was drawn on the highest sugar content of internode 1 of the control T×430. $\mathbf{a}$ The controls T×430; $\mathbf{b} T r a n s g e n i c ~ l i n e$ A2; c Transgenic line A5; and $\mathbf{d}$ Transgenic line L9

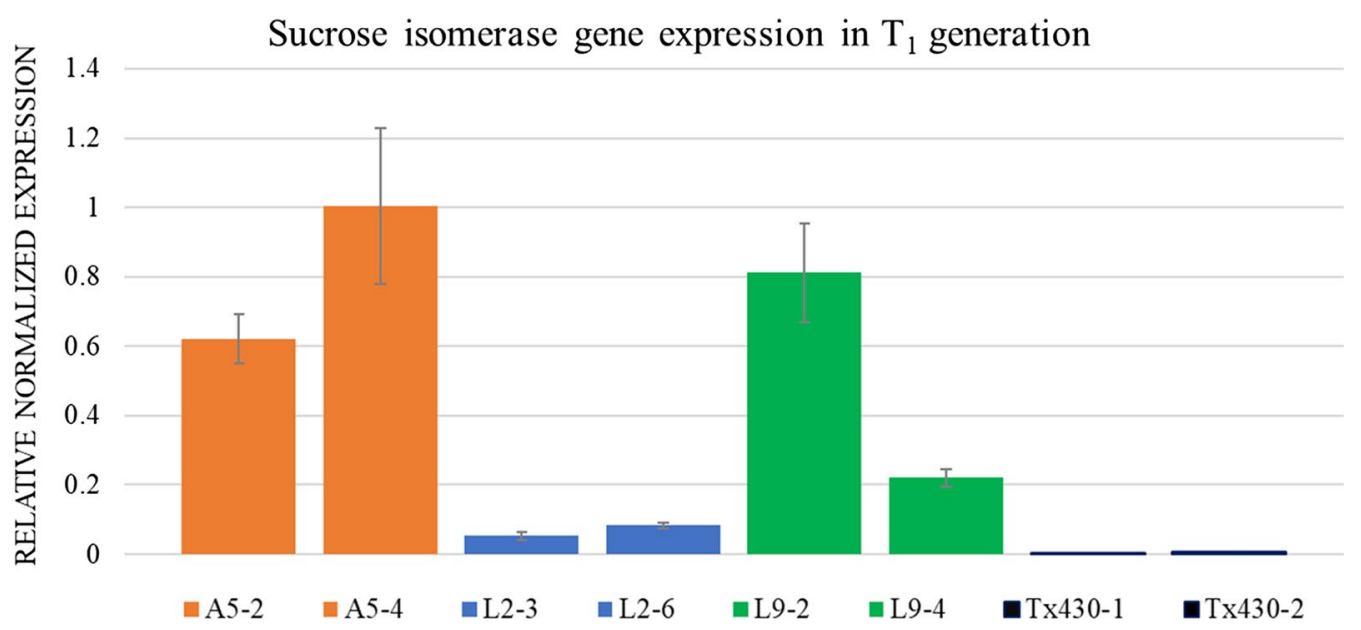

Fig. 4 RT-PCR analysis of the $S /$ gene expression in $T_{1}$ progenies and $T \times 430$. Six SI-positive $T_{1}$ lines are from three $T_{0}$ transgenic events. A5 $T_{1}$ progenies: A5-2 and A5-4; L2 T, progenies: L2-3 and L2-6; L9T, progenies: L9-2, and L9-4; T×430-1, T×430-2 are non-transgenic control samples. The error bars presented the variation in three biological replicates 
High sugar contents were inherited in $\mathrm{F}_{\mathbf{1}}$ hybrids

The elite sweet sorghum cultivar R9188, and Rio were selected as female lines for crossing due to their advantages of large biomass and high-sucrose content in stalks. Transgenic lines A5, and L9 were chosen as male lines because of their superior performance on isomaltulose accumulation and high total sugar content. Crosses were performed with the male-sterile lines of R9188, and Rio. Hybrid seeds were harvested from successful crossing.

Thirty seeds of hybrids of Rio X L9 were sown in pots along with the controls of Rio, R9188, and $\mathrm{T} \times 430$ in the glasshouse. The sweet sorghum cultivar R9188 is another version of Rio with an extra dwarf gene, hence almost $50 \mathrm{~cm}$ shorter. Hybrid seed germination and early seedling growth were similar to the controls, except one hybrid seed which did not germinate. Sugar profiles of HPLC showed that among 29 progenies of $F_{1}$ generation, isomaltulose was detected in 15 progenies (51.7\%) and no isomaltulose was detected in the rest of 14 samples $(48.3 \%)$. The ratio of positive to negative samples was close to the predicted 1:1 ratio (Fig. 5), indicating hybrid seeds inherited the $S I$ gene as a single genetic locus from the parent L9.

Within the 15 isomaltulose positive group, three progenies converted almost all sucrose into isomaltulose; six converted more than $65 \%$ of sucrose; two converted about $33 \%$ of sucrose; four had less than $1 \%$ sucrose converted (Fig. 5). Notably, the improvement of total sugar content was observed in most isomaltulose positive lines (Fig. 5). The increase of total sugar content was on average $37 \%$ higher than the sweet sorghum Rio. The increase ranged from 484 to $932 \%$ if compared with the grain sorghum $\mathrm{T} \times 430$, which is in agreement with the results of the $\mathrm{T}_{0}$ generation (Fig. 2).

Another hybrid population of R9188 X L9 were planted as well. It showed similar pattern as the population of Rio $\mathrm{X}$ L9. Among $26 \mathrm{~F}_{1}$ population, 12 of them are positive for sucrose isomerase gene (Additional file 1: Table S2). The highest total sugar content at $764 \mathrm{mM}$ was measured in $\mathrm{F}_{1}$ L9R9-20 line and the top isomaltulose content at $565 \mathrm{mM}$ was detected in the $\mathrm{F}_{1}$ L9R9-9 line. By comparison, remarkably higher total sugar contents were monitored in positive $S I$ lines (on average $538 \mathrm{mM}$ ) than negative $S I$ lines (on average 342 ), which means the sugar content has been improved $57.3 \%$ thanks to the SI gene. While the average sugar content in the sweet sorghum R9188 and grain $\mathrm{T} \times 430$ were 261 and $93 \mathrm{mM}$, respectively. The detail of results was shown in Additional file 1: Table S2.

\section{High sugar contents were inherited in $\mathrm{F}_{\mathbf{2}}$ population}

Based on isomaltulose concentration, total sugar content, stalk biomass, and seed production, $\mathrm{F}_{1}$ (Rio X L9) progenies LR3, LR19 and LR20 were selected for further characterization. With the parental controls of sweet sorghum Rio, progeny LR24, a null segregant with comparative high sugar content was also selected as a hybrid control. Seeds were produced by self-pollination.

Sugar profiles of the isomaltulose positive plants showed that they inherited the phenotype of high isomaltulose and high sugar content (Fig. 6). In all SI positive progenies, isomaltulose accumulated at high levels in

\section{Sugar profiles in $\mathrm{F}_{1}$ generation (L9 $\times$ Rio)}

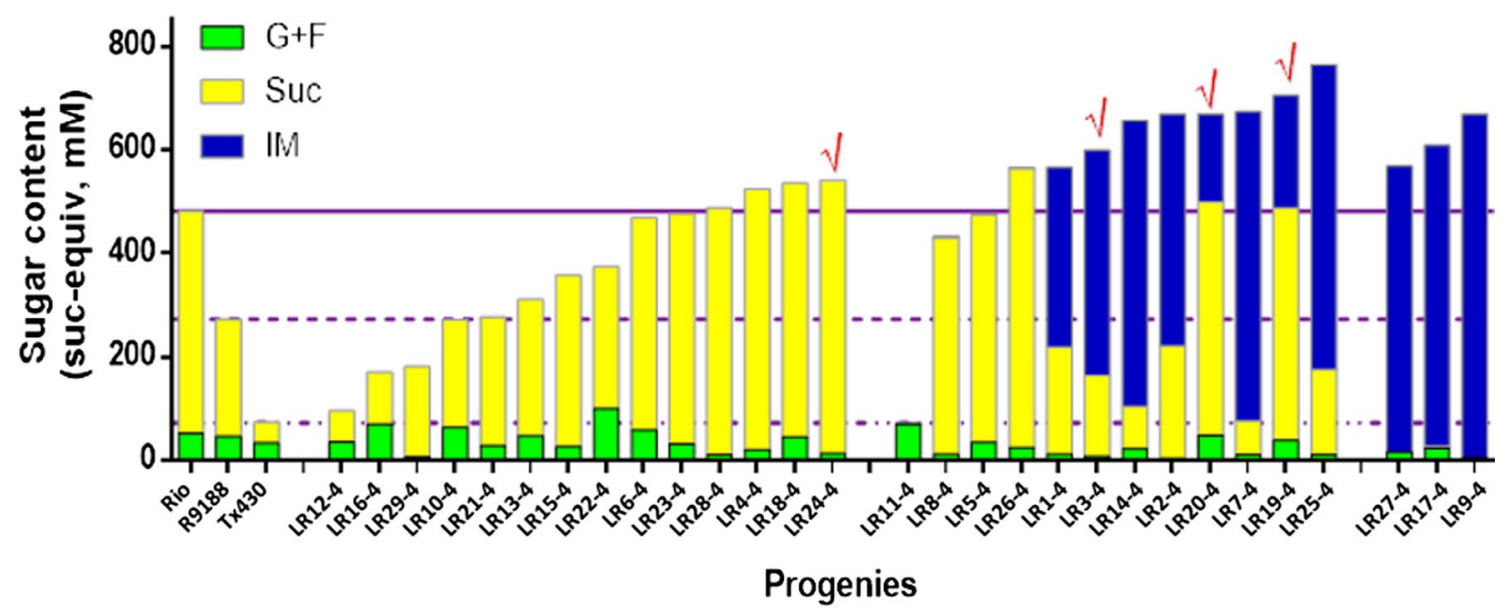

Fig. 5 Total sugar content in the $F_{1}$ hybrids (Rio X L9). Sugars were measured 20-day post-anthesis in the middle section of internode 4 (counted from top). L9 is the transgenic line driven by LSG2 promoter. G + F: 1/2 (Glucose plus fructose); Suc: Sucrose; IM: Isomaltulose. Bars of the controls Rio, R9188, and T×430, were means of three stalks. Three horizontal lines represent the average of the three controls, respectively. The progenies with red ticks $(\sqrt{ })$ were selected for further testing 


\section{Sugar profiles of controls and some $F_{2}$ progenies}

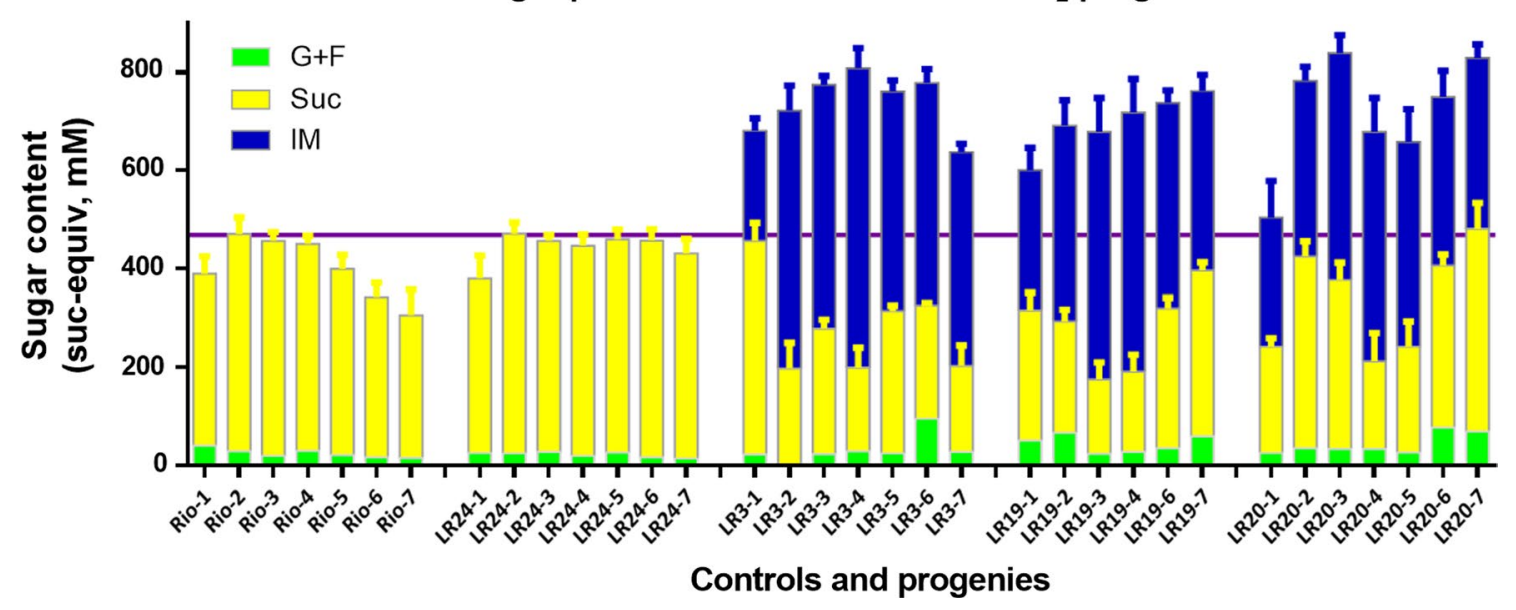

Fig. 6 Sugar profile of internodes in controls and selected progenies of the $F_{2}$ generation (Rio X L9). The first group (Rio-1 to 7) represents the parent Rio control, the second group LR24 (LR24-1 to 7) represents the transgene negative control $F_{2}$ progenies, and the rest three groups are $P C R$ positive $F_{2}$ progenies from LR3, LR19 and LR20. The last digit in the label of the X-axis is the internode number counted from the top. G+F: $1 / 2$ (Glucose plus fructose); Suc: Sucrose; IM: Isomaltulose. Sugars were measured 20-day post-anthesis in the middle section of each internode. Results were means with standard errors from three replicates. The horizontal line was drawn on the highest total sugar content among all internodes of the Rio control

all internodes. In addition, sucrose content were stored at comparable levels (total sugar content up to $812.2 \mathrm{mM}$ ), resulting in up to $69 \%$ increase of total sugar content compared to the parental $(480.6 \mathrm{mM})$ or the hybrid control (470.9 mM) (Fig. 6).

\section{Sugar content was increased, whereas water content was decreased in $\mathrm{F}_{\mathbf{2}}$ stalk juice}

Carbon partitioning into sugars and fiber was estimated in the selected $\mathrm{F}_{2}$ progenies and controls. There was more sugar per unit fresh weight $(\mathrm{FW})$ in all internodes of the tested high-sugar progenies than the controls (Fig. 7a). In the sweet sorghum Rio and hybrid null segregant LR24, the water content was typically constant around $75 \%$ along the stalk with a slight increase in the bottom internodes; however, in the stalks of three high-sugar progenies, water content was significantly lower around $70 \%$ (Fig. 7b). Moreover, there were no significant change in the fiber content among all samples, which was around $11 \%$ in internode tissues (Fig. 7). These results indicated that instead of alteration of fiber and sugar, assimilation was improved and more sugar was stored in the progenies LR3, LR19, and LR20 than the controls. Therefore, the commercially important trait of high sugar content in juice from the selected progenies are underpinned by increasing sugar content and decreasing water content in the mature stalk.

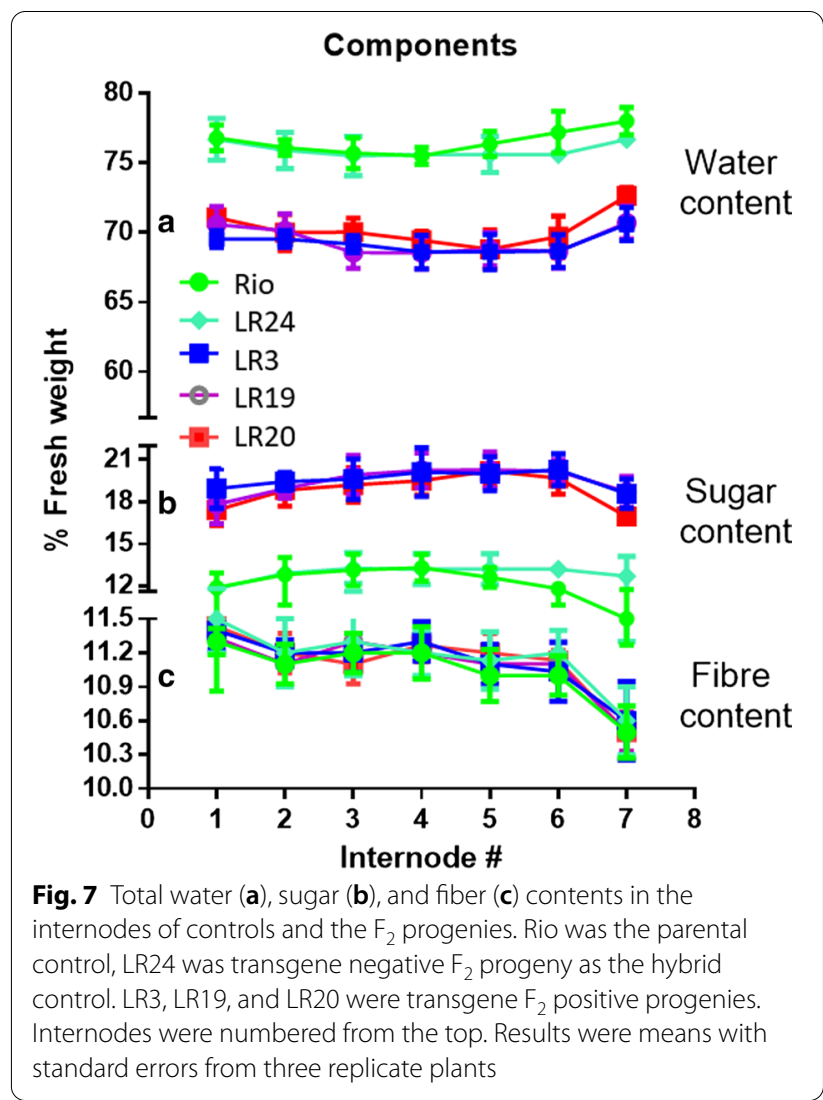


Photosynthesis was increased in high sugar $F_{2}$ lines Two key physiological characteristics, including photosynthetic electron transport and $\mathrm{CO}_{2}$ assimilation, were examined to understand the mechanisms of enhanced sugar accumulation. Rates of leaf electron transport and $\mathrm{CO}_{2}$ assimilation of the progenies LR3, LR19, and LR20 were higher than the controls Rio, $\mathrm{T} \times 430$ and hybrid control LR24. The photosynthetic electron transport rate and $\mathrm{CO}_{2}$ assimilation rate were measured by chlorophyll fluorescence (reflecting photosynthetic efficiency in photosystem II). The both rates were improved by $20 \%$ to $35 \%$ in high sugar content $F_{2}$ lines compared to the controls at different photosynthetically active radiation (PAR) levels (Fig. 8). Light response curves from the fully expanded leaf 2 are measured (Fig. 8). Moreover, the senescence of the bottom leaves on each stalk of the high sugar progenies was typically delayed by $2-3$ weeks, resulting in leaf functional extension in photosynthesis.

\section{Sugar transport was improved in source leaves and sink} tissues

Rate of proton gradient-dependent sucrose transport into plasma membrane vesicles (PMV) is an indicator for sucrose uploading in the source leaves [36]. The isolated PMVs from leaf 2 and 3 of the selected high-sugar progenies LR3, LR19, and LR20 were $20 \%$ to $40 \%$ higher than that of controls (null segregant LR24, parents Rio and $\mathrm{T} \times 430$ ), indicating the driving power of loading assimilation for transport was improved (Fig. 9a) in the source leaves of the high-sugar progenies.

Sorghum phloem in a stem vascular bundle is symplasmically isolated from the surrounding parenchyma cells, and the sucrose unloading is apoplasmic [37]. Cell wall invertase (CWI) activity is a determinant of sucrose gradient in the unloading area. In all tested internodes, CWI activities of the central storage parenchyma-rich zone were significantly higher in the high-sugar progenies than in the controls LR24, Rio and T $\times 430$ (Fig. 9b), but not in the peripheral vascular-rich zone (Fig. 9c). When the vascular bundles were dissected from the storage parenchyma cells in the central zone of internode 5 and assayed separately, the increased CWI activity in the high-sugar progenies was clearly restricted to the storage parenchyma (Fig. 9d), indicating the abilities on assimilate was increased within the sink tissues of the highsugar progenies.

\section{Discussion}

The present study demonstrated that notably higher sugar contents (over $750 \mathrm{mM}$ ) were achieved in transgenic grain sorghum $\left(T_{0}\right.$, and $\left.T_{1}\right)$ and sweet $x$ grain sorghum hybrids $\left(\mathrm{F}_{1}\right.$, and $\left.\mathrm{F}_{2}\right)$, which is similar or higher than the sugar content of field-grown sugarcane (600$700 \mathrm{mM}$ ). The high sugar content, which was detected by HPLC in $T_{0}, T_{1}, F_{1}$, and $F_{2}$ plants, displayed that the phenotype of high level of sugar accumulation was stably inheritable. This study displayed that sucrose isomerase can efficiently convert sucrose into isomaltulose and dramatically increase total sugar content in sorghum. In addition, the superior engineered progenies had significantly higher photosynthesis, higher sucrose transport, and higher sink strength than the controls, which could be the key drivers for higher sugar accumulation in plants. This approach provides a new perspective on the plant source-sink relationship. It could have a substantial impact on producing high-value sugar isomaltulose and
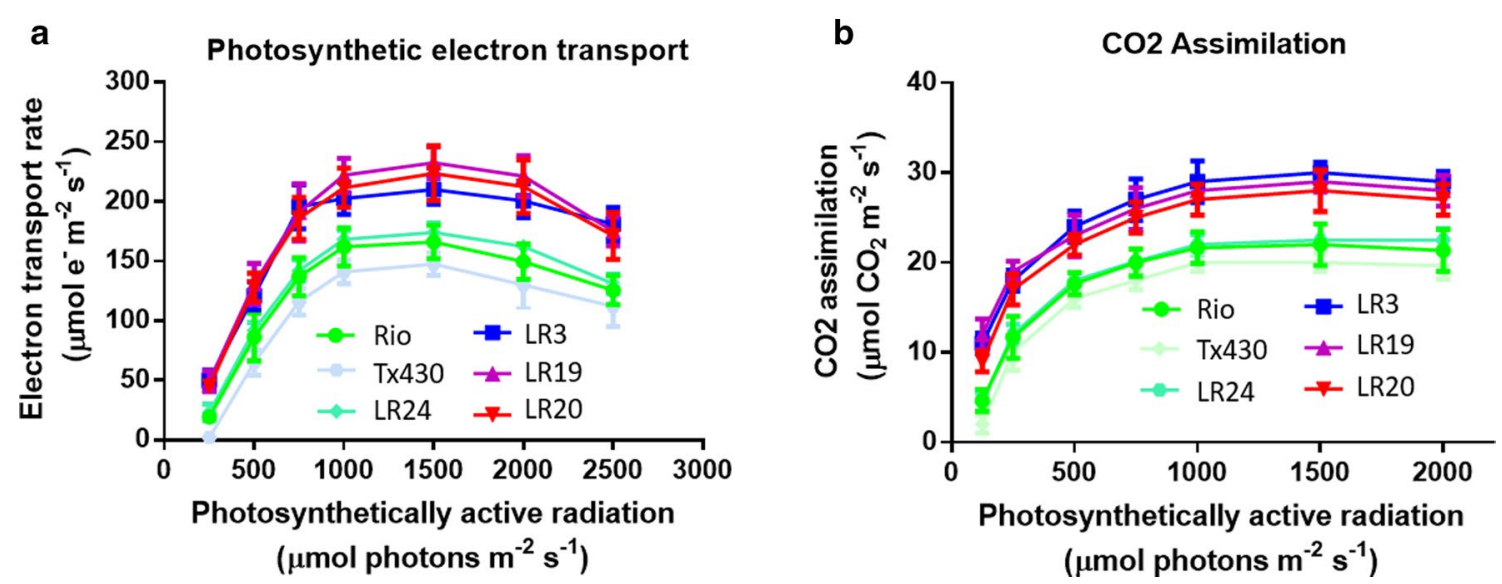

Fig. 8 Photosynthetic electron transport rate (a) and $\mathrm{CO}_{2}$ assimilation (b) in controls and the $\mathrm{F}_{2}$ progenies. Three controls: Rio (parental control), $T \times 430$ (untransformed control), LR24 was transgene negative $F_{2}$ progeny as the hybrid control. Three high-sugar transgene $F_{2}$ positive progenies: LR3, LR19, and LR20. Photosynthesis was measured in the second leaf from the top after 10-11-day post-anthesis. Results were means with standard errors from three replicates 


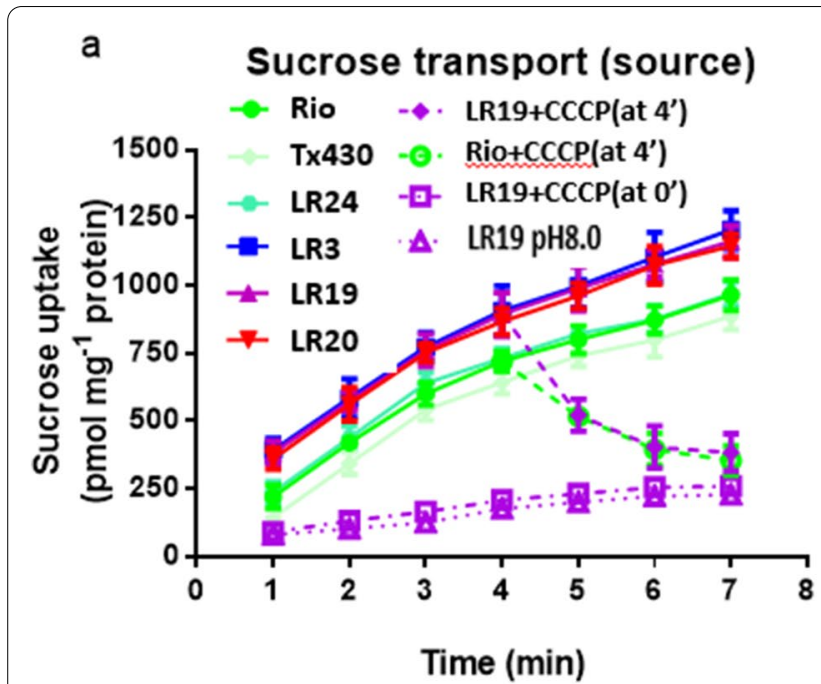

c Peripheral zone CWI (sink)

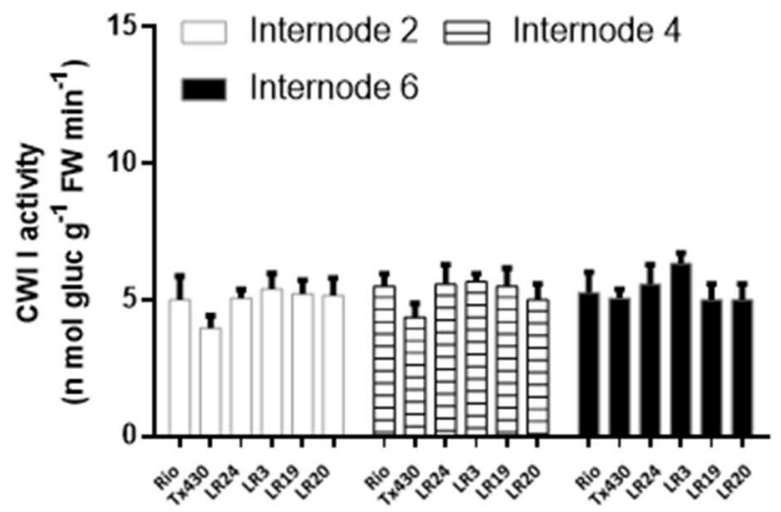

Controls and progenies

\section{b Central zone CWI (sink)}

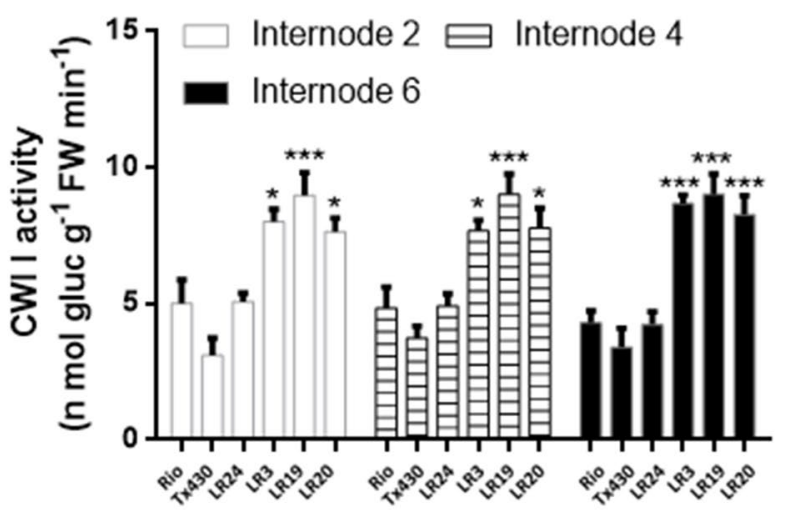

Controls and progenies

\section{d Parenchyma vs vascular CWI (sink)}

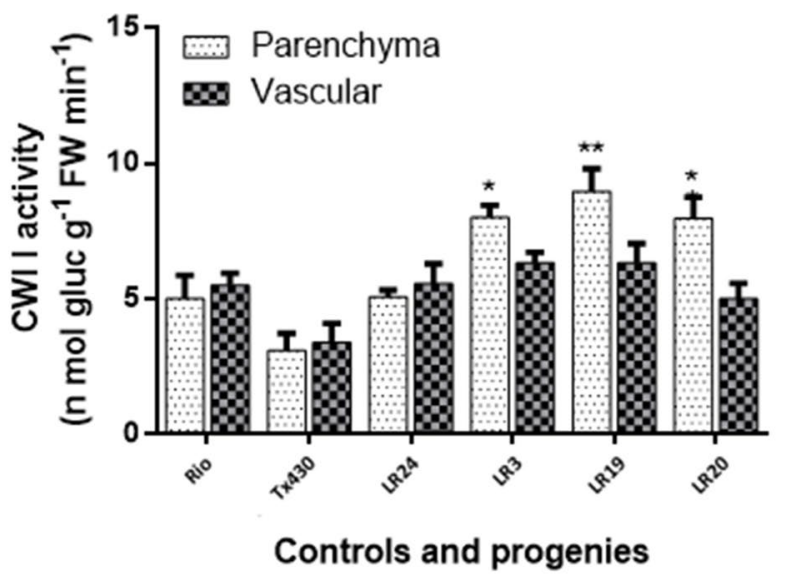

Fig. 9 Relationship of source and sink in controls and the $F_{2}$ progenies. a sucrose transport (source). b CWI activity was measured in the central parenchyma-rich zone (sink). $\mathbf{c}$ in the peripheral vascular-rich zone (sink). $\mathbf{d}$ in separated vascular bundles and parenchyma tissue from the central zone of internode 5 (sink). Three controls: Rio (parental control), $T \times 430$ (untransformed control), LR24 was transgene negative $F_{2}$ progeny as the hybrid control. Three high-sugar transgene $F_{2}$ positive progenies: LR3, LR19, and LR20. CCCP: carbonyl cyanide m-chlorophenyl hydrazone. The leaves and internodes were sampled at 20 days after anthesis. Results are means with standard errors from three replicates. Analysis of variance (ANOVA) with Bonferroni post-tests showed significant differences between any control and high-sugar progenies in the sucrose transport rates at all time points. The same statistical analysis showed significant differences between controls and high-sugar progenies in $\mathrm{CWI}$ activity of parenchyma cells in the central zone. ${ }^{*} P<0.05$; ${ }^{* *} P<0.01 ;{ }^{* *} P<0.001$

have enormous potential for renewable feedstcoks for bio-energy.

The current research on sorghum is beneficial from previous study on sugarcane. Firstly, sucrose depletion was avoided by targeting the $S I$ enzymes into sucrosestorage vacuoles [38]. Secondly, the disturbance on normal growth/functions of other organs was circumvented using stem-specific expression of the $S I$ gene $[31,35]$. Finally, the $S I$ gene sequence was modified to remove the motifs that trigger silencing in plants [31, 39]. To our best knowledge, this would be the first report on engineering SI in sorghum, or any other cereal. Sweet sorghum has been considered as a biofuel and biomass crop [13]. Our results displayed that sugar content can be increased up to $69 \%$ in hybrids compared with sweet sorghum, which will bfoost industrial value at large scale.

The activity of the vacuole-targeted SI enzyme was undetectable in cell extracts, because the sucrose-storage 
vacuoles are highly acidic and proteolytic. Rapid degradation of vacuole-targeted SI presumably protects against running out of sucrose in growing tissues. It is believed that isomaltulose accumulates gradually in the stalk during development, probably due to following reasons: (i) constant transcription of $S I$ driven by the strong stemspecific $L S G 2$ or ScR1MYB1 A1 promoter [31, 35]; (ii) high catalytic efficiency allowing occasional isomaltulose production before $S I$ inactivation [24]; and (iii) very slow isomaltulose metabolism by plant enzymes [40]. For commercialization of this valued sugar, it is essential to achieve proper patterns of developmental expression, cell compartmentation, and enzyme stability to yield high isomaltulose content in stalks.

There has been an ongoing discussion as to whether current sugar crops have reached a physiological plateau with respect to sugar accumulation [41]. Compared to the sugar content of field-grown sugarcane juice (600$700 \mathrm{mM})$, high-level sugar accumulation (>1000 mM disaccharides content), containing isomaltulose production (up to $691 \mathrm{mM}$ ) in stalk juice of the transgenic line in this study, sheds lights on that the assumed 'ceiling' above sugar accumulation could be exceeded.

Transgenic sorghum lines provide new insightful information on mechanisms as to how plants regulate sugar accumulation, a pivotal question in plant biology [42-45]. The phenotype of high total sugar content is attributed to delaying leaf senescence, increasing photosynthetic activity, and enhancing sucrose loading rates in source tissues, as well as higher activity in stalk storage parenchyma of CWI, which has multiple roles in sink tissues $[44,46]$. Each of these activities would make a contribution to high sugar yield. Further comparative analysis of the superior lines and their parent lines could reveal key molecular and physiological control points in plant source-sink flux. As all the reported experiments were undertaken under well-watered, temperature-control glasshouse conditions, it is essential that further field trial should be undertaken, given the considerable diurnal and seasonal temperature variations, as well as water and nutrient availability.

Sweetness is an important commercial trait in many food crops. Enhancing sweetness through a slowly digested, acariogenic sugar, such as isomaltulose, can bring direct health benefits for consumers [18]. Isomaltulose is naturally present at a very low level (0.1$0.7 \%$ ) in honey and sugarcane extracts which are too small to be extracted [18]. In this study, isomaltulose can be accumulated at a notably high level $(691 \mathrm{mM})$ in transgenic sorghum lines. It could be harvested and extracted at the commercial scale in the future.

The fermentable carbohydrate content is also a key determinant of the economic and environmental feasibility of renewable biofuel production $[47,48]$. Sweet sorghum is widely considered as a biofuel crop [1]. Accumulation of higher sugar content would increase the economic value of renewable energy. In the long term, sugars ultimately underpins all other biosyntheses in plants. The sugar boosting effect of the SI gene may be a foundation for higher sugar yields of many other bioenergy materials.

\section{Conclusion}

Significant progress has not been made in sugar content among sugar crops for decades. The genetic engineering has shed lights on improving sugar content of sugar crops. The SI gene has been successfully transformed into sorghum and drastically improved total sugar content (up to $1000 \mathrm{mM}$ ) in sorghum. Generally, the total sugar content ranges 400 to $500 \mathrm{mM}, 600$ to $700 \mathrm{mM}$ in stalk juice of sweet sorghum and sugarcane, respectively. Remarkably, the high sugar contents (more than $750 \mathrm{mM}$ ) were measured in multiple transgenic events (A5, A51, A52, L3, L7, L9 and L16) and multiple generations $\left(\mathrm{T}_{0}, \mathrm{~T}_{1}, \mathrm{~F}_{1}\right.$, and $F_{2}$ ). The total sugar content in $F_{1}$ and $F_{2}$ generations have been improved 57 and $69 \%$, respectively, compared with the elite sweet sorghum Rio (close to $500 \mathrm{mM}$ ). Those total sugar contents of elite engineered lines have exceeded the sugar content of field-grown sugarcane. The massive increase of sugar accumulation in sorghum would boost its biofuel production at the commercial scale. More importantly, the results illustrated that the phenotype of high sugar content is inheritable and reliable. Additionally, the high sugar accumulation did not show any deleterious effect on plant growth morphologically in the elite engineered lines. These results demonstrate that genetic engineering on sorghum has considerable potential for biofuel and bio-industry.

\section{Materials and methods \\ Constructs of sucrose isomerase gene}

Constructs were prepared by recombining four parts. The first part is a $1.2 \mathrm{~Kb}$ sugarcane ScR1MYB1 A1 promoter (GenBank EU719199) [31] or a sugarcane loading stem gene promoter (LSG2, GeneBank JQ920356) [35]. The second part is a fragment encoding signal peptide of sweet potato sporamin NTPP as described in the reports $[30,38]$. The third part is a modified gene version (GenBank KC147726) encoding the UQ68J SI enzyme [24, 31]. The fourth part is a terminator complex including three contiguous plant transcriptional terminator regions which are intended to block read-through transcription in either direction [31] (Additional file 1: Fig. S2).

\section{Sorghum transformation}

Sweet sorghum has been considered as one of the most recalcitrant crops in terms of genetic transformation 
[33]. To successfully introduce the engineered SI construct into the large biomass sweet sorghum lines, an inbred line of grain sorghum $\mathrm{T} \times 430$ was first transformed. Then the $T \times 430$ transgenic lines were used as male parents for crossing with elite sweet sorghum cultivars Rio, and R9188 as female parents. Rio and R9188 are advantageous for large biomass and have been used as male-sterile parents in sorghum breeding projects. R9188 is shorter than Rio.

Plasmids containing the sucrose isomerase gene driven either by $L S G 2$ promoter or $S c R 1 M Y B 1 A 1$ promoter, are co-precipitated on gold particles with $p U K N$ construct $[39,49]$. Transformation protocol by particle bombardment, selection of transgenic lines, plant regeneration, and growth conditions in the glasshouse were described as GQ Liu, BC Campbell and ID Godwin [49]. Briefly, embryogenic calli derived from immature embryos (1115-day post-anthesis) were used as explants for transformation. Transformed calli were cultured for 8-12 weeks on selective regeneration media containing $30 \mathrm{mg} \mathrm{L}^{-1}$ geneticin with subculturing fortnightly. Putative transgenic shoots were subsequently subcultured onto selective rooting media for 4 weeks following by 3-day acclimation. Details of the sorghum tissue culture were as described by GQ Liu, EK Gilding and ID Godwin [50].

\section{PCR screening}

Genomic DNA was extracted from the young leaves of the transgenic and non-transgenic plantlets prior to potting out in the glasshouse. Extracted DNA quality and concentration were determined using a NanoDrop 2000 spectrophotometer (Thermo Scientific). To confirm the sucrose isomerase $(S I)$ gene, specific primers were designed (Forward: 5'-AGCAACCCGATCTCAACT GG-3' and Reverse: 5'-ACGGAGTCGTTCCATTGC AT- $\left.3^{\prime}\right)$. PCR screening was undertaken in $20 \mu \mathrm{l}$ reaction each containing $20 \mathrm{ng}$ of template DNA, $0.5 \mu \mathrm{M}$ of each specific primer and $10 \mu \mathrm{l}$ of Taq $2 \times$ Master Mix (New England BioLabs). PCR reactions were performed using a BIO-RAD T100 Thermal Cycler ${ }^{\circledR}$. The PCR program comprised of an initial denaturation at $95{ }^{\circ} \mathrm{C}$ for $7 \mathrm{~min}$, followed by 35 amplification cycles consisting of; $95{ }^{\circ} \mathrm{C}$ for $30 \mathrm{~s}, 60^{\circ} \mathrm{C}$ for $30 \mathrm{~s}, 72^{\circ} \mathrm{C}$ for $1 \mathrm{~min}$, and a final elongation step of $72^{\circ} \mathrm{C}$ for $7 \mathrm{~min}$. PCR products were separated by $1.0 \%$ gel electrophoresis at $120 \mathrm{~V}$ for $1.5 \mathrm{~h}$ (Additional file 1: Fig. S3).

\section{Growth conditions and crossing}

Following the hardening off period, SI-positive transgenic plantlets and negative controls were transferred to $20-\mathrm{L}$ pots with three plantlets. Pots were randomized and grown in a temperature-controlled glasshouse (18$28{ }^{\circ} \mathrm{C}$ ) for around 95 days until physiological maturity.
Generally, transgenic plants and the controls started flowering 60 days after moving into the glasshouse. The transgenic plants grew as healthily as the control plants in morphology (Additional file 1: Fig. S1). Sweet sorghum seeds of Rio, and R9188 were sowed in the same glasshouse in different batches with 2-week interval to meet the flowering time of the elite transgenic lines for crossing. The crossing was performed as described [51].

\section{Measuring sugar content by high-performance liquid chromatography electrochemical detection (HPLC-ED)}

For stalk samples, a transverse tissue slice was taken at the mid-point of each designated internode and cut into radial sectors that were proportionately representative of the different stalk tissues. Sectors were placed on a support screen (Promega Spin Basket, Madison, WI) within a $1.5-\mathrm{mL}$ microfuge tube. Samples were frozen by liquid nitrogen for $20 \mathrm{~min}$, and then were thawed on ice and centrifuged at $10000 \mathrm{~g}$ for $15 \mathrm{~min}$ at $4{ }^{\circ} \mathrm{C}$ to collect the stem juice. After that, juice was boiled for $5 \mathrm{~min}$ to inactivate enzymes. The insoluble material was removed by centrifugation at $16000 \mathrm{~g}$ for $20 \mathrm{~min}$ at $4{ }^{\circ} \mathrm{C}$. The comparative tests were conducted on internodes before. Sugar concentrations, measured from this procedure, are equivalent to the sugar content from the juice which was crushed manually. Moreover, this procedure was adaptable to large scale samples. FWs were recorded before and after juice extraction and residual dry weights (DWs) were measured after $72 \mathrm{~h}$ at $75^{\circ} \mathrm{C}$ for tissues, or $90{ }^{\circ} \mathrm{C}$ for juice samples. Water contents were measured as well.

The resolution and quantification of isomaltulose, trehalulose, sucrose, glucose and fructose were achieved by isocratic HPLC at high $\mathrm{pH}(120 \mathrm{mM} \mathrm{NaOH})$, using a Dionex BioLC system (Sunnyvale, CA) with PA20 analytical anion exchange column and quad waveform pulsed ED, with calibration against a dilution series of sugar standards for every sample batch $[15,38]$. Sugar concentrations were calibrated in the procedure and presented as sucrose equivalents in juice. Total sugar contents were calculated on an FW and DW basis, taking account of the residual juice in internode tissues after centrifugation (up to $60 \%$ of total juice) and assuming $10 \%$ reduction in solute concentration in residual juice relative to first extracted juice [52]. For leaf samples, about $1 \mathrm{~g} \mathrm{FW}$ of leaf without midrib was taken at one-third of the distance from the dewlap to the leaf tip. For root samples, about $0.5 \mathrm{~g} \mathrm{FW}$ of young roots was taken from the interface between the soil and pot. Fluids were extracted and assayed by the same freeze-thaw-centrifuge-HPLC method described above for stalk samples. 
qRT-PCR of the $\mathbf{S I}$ gene expression in $\mathrm{T}_{\mathbf{1}}$ generation The $\mathrm{T}_{1}$ progeny fresh leaf samples of A5, L2, L9, and $\mathrm{T} \times 430$ (the wild-type control) were collected from the glasshouse. Leaf samples were ground using liquid nitrogen. The DNA extraction kit (ISOLATE II Plant DNA Kit, BIOLINE Cat No. Bio-52070) was used and the protocol was utilized to obtain total genomic DNA for identifying positive progenies of NPTII and SI genes. The RNA extraction kit (ISOLATE II RNA Mini Kit, BIOLINE BIO-52072) was utilized to obtain total RNA from the fourth internode of positive $\mathrm{T}_{1}$ plants 20-day post-anthesis. For real-time PCR, the total RNA was transcripted into cDNAs (GoScript ${ }^{\mathrm{TM}}$ Reverse Transcription, Promega, REF A5001). Then the GoTaq 1-Step RT-qPCR (Promega REF A6021) was deployed in the Bio-RAD CFX96 ${ }^{\mathrm{TM}}$ RealTime System C1000 Touch $^{\mathrm{TM}}$ Thermal cycler. RT-PCR SI primers (SI-forward: CGACATCAGCGACTACAG GA; SI-reverse: CCTTGGAAGATGAACGGTGT) were used to quantify the amount of SI transcript, which was expressed relative to the reference gene sorghum elongation factor 1-alpha (Sb02g036420; amplification of the reference gene using primers REF-forward: CCCAAG TACTCCAAGGCTCG and REF-reverse: ATGTTGTCA CCCTCGAACCC). The data was analysed using LinRegPCR (Ramakers et al. 2003). Three biological replicates of each sample were used for RT-PCR.

Gas exchange and chlorophyll fluorescence measurements The photosynthetic electron transport rate was estimated from the fluorescence light curve generated using a fiberoptic MINI-PAM/F (Heinz Waltz GmbH, Effeltrich, Germany) and leaf-clip holder 2030B positioned at one-tenth of the distance from the dewlap to the leaf tip. The MINIPAM light intensity, saturation pulse intensity, saturation pulse width, leaf absorption factor and illumination time were set at $680 \mu \mathrm{mol} / \mathrm{m} 2 / \mathrm{s}, 680 \mu \mathrm{mol} / \mathrm{m} 2 / \mathrm{s}, 0.8 \mathrm{~s}, 0.84$ and $10 \mathrm{~s}$, respectively. The internal temperature of the MINI-PAM was controlled between 25 and $30{ }^{\circ} \mathrm{C}$ during measurement. An LI-6400 portable photosynthesis system (LI-COR, Lincoln, NE, USA) was used to measure $\mathrm{CO}_{2}$ fixation rates on the same leaves. Measurements were performed on more than three replicate plants per progeny.

Plasmalemma vesicle (PMV) isolation and transport assays The blades of the second and third leaves from the top without midribs (12.5 g FW) were homogenized in $50 \mathrm{~mL}$ solution which contains $240 \mathrm{mM}$ sorbitol, $50 \mathrm{mM}$ N-2-hydroxyethylpiperazine-N' 2-ethanesulphonic acid (HEPES), $3 \mathrm{mM}$ ethyleneglycol-bis (ßaminoethylether)- $N, \quad N$-tetraacetic acid (EGTA), $3 \mathrm{mM}$ dithiothreitol (DTT), $10 \mathrm{mM} \mathrm{KCl,} \mathrm{0.5 \%} \mathrm{bovine}$ serum albumin (BSA), 0.6\% polyvinylpyrrolidone (PVP) and $2 \mathrm{mM}$ phenylmethyl sulphonyl fluoride (PMSF) (adjusted to $\mathrm{pH} 8.0$ using solid Bistris propane) at $4{ }^{\circ} \mathrm{C}$. The homogenate was filtered through four layers of cheesecloth to remove tissue debris and then centrifuged at 10,000 $\mathrm{g}$ for $10 \mathrm{~min}$ to remove mitochondria and chloroplasts. Microsomal membranes were pelleted by centrifugation at $50000 \mathrm{~g}$ for $60 \mathrm{~min}$. PMVs were purified from the microsomal fraction by phase partitioning [36], washed in $25 \mathrm{~mL}$ of sorbitol-based re-suspension buffer (SBRB) (330 mM sorbitol, $2 \mathrm{mM}$ HEPES, $0.1 \mathrm{mM}$ DTT, $10 \mathrm{mM} \mathrm{KCl}, \mathrm{pH} 8.0$ with solid Bistris propane), repelleted by centrifugation at $50,000 \mathrm{~g}$ for $60 \mathrm{~min}$ and resuspended at 3-5 $\mathrm{mg} \mathrm{FW} \mathrm{mL}^{-1}$ of re-suspension buffer. The phasepurified PMVs were layered over a 20 to $50 \%$ sucrose gradient in $2 \mathrm{mM}$ HEPES, $1 \mathrm{mM} \mathrm{HCl}$ and $1 \mathrm{mM}$ DTT (pH 8.0 with solid Bistris propane), centrifuged at $100000 \mathrm{~g}$ for $15 \mathrm{~h}$ and collected in $1-\mathrm{mL}$ fractions. The fractions were washed in $11 \mathrm{~mL}$ SBRB and pelleted by centrifugation at $100000 \mathrm{~g}$ for $60 \mathrm{~min}$. The pellet was suspended in $0.4 \mathrm{~mL}$ of SBRB. The purity of samples was checked using routine tests for enzymatic activities of other cellular membrane types.

Transport assays were conducted at $12{ }^{\circ} \mathrm{C}$ using three replicate reactions per treatment (Bush et al., 1996). Briefly, for each reaction mixture, $20 \mu \mathrm{L}$ of resuspended PMVs were diluted into $400 \mu \mathrm{L}$ of assay buffer (as for SBRB, except adjusted to $\mathrm{pH} 6.0$ with solid 2 [N-morpholino ethane sulphonic acid (MES)] containing $0.2 \mu \mathrm{Ci}$ $\left({ }^{14} \mathrm{C}\right)$ sucrose and unlabelled sucrose to the desired concentration. At each time point, vesicles from one reaction mixture were collected on $0.45-\mu \mathrm{m}$ filters and rinsed three times with $0.6 \mathrm{~mL}$ of assay buffer containing only unlabelled sucrose $(1 \mathrm{mM})$. The accumulated radioactivity was measured by scintillation spectrometry. The difference between samples with and without $5 \mu \mathrm{M}$ carbonyl cyanide $m$-chlorophenyl hydrazone (CCCP) was defined as $\Delta \mathrm{pH}$-dependent sucrose transport.

\section{Internode tissue fractionation and enzyme assays}

Transverse sections of each internode were divided into the outer rind of $2 \mathrm{~mm}$ thickness and two internal concentric cylinders at equal distances along the stalk radius. Of these, the central parenchyma-rich zone and the peripheral vascular-rich zone were examined for invertase activity. Furthermore, vascular bundles were separated by dissection from parenchyma tissue in the central zone for separate assays. The separated tissues were frozen immediately in liquid nitrogen for enzyme extraction, followed by the determination of CWI activity. Three replicate plants or dissected tissue subsamples were used for each assay [53].

The SI enzyme was extracted by grinding the frozen cells in a chilled mortar using three volumes of 
extraction buffer that contained $0.1 \mathrm{M}$ Hepes-KOH buffer(pH7.5), $10 \mathrm{mM} \mathrm{MgCl} 2,2 \mathrm{mM}$ EDTA, $2 \mathrm{mM}$ EGTA, $10 \%$ glycerol, $5 \mathrm{mM}$ DTT, $2 \%$ polyvinylpolypyrrolidone and $1 \times$ complete protease inhibitor (Roche, Mannheim, Germany). The homogenate was immediately centrifuged at $10000 \mathrm{~g}$ for $15 \mathrm{~min}$ at $4{ }^{\circ} \mathrm{C}$. The supernatant was immediately desalted on a PD-10 column (GE Healthcare, Buckinghamshire, UK) that was pre-equilibrated and eluted using the extraction buffer. Protein concentration was assayed by the Bradford reaction using a Bio-Rad kit (Hercules, CA, USA) with bovine serum albumin standards. SI activity was measured by incubating enzyme extract with $292 \mathrm{mM}$ sucrose solution in $0.1 \mathrm{M}$ citrate-phosphate buffer $(\mathrm{pH}$ 6.0) at $30^{\circ} \mathrm{C}$.

\section{Supplementary Information}

The online version contains supplementary material available at https://doi. org/10.1186/s13068-021-01907-z.

Additional file 1: Fig. S1. Transgenic sorghum lines were grown in a PC2 glasshouse. (a) 1 week; (b) 2 weeks; (c) 3 weeks; (d) 5 weeks; (e) 7 weeks; (f) 10 weeks in the glasshouse; (g) mature T×430; (h) mature A5; ( $f$ ) mature L9. Fig. S2. The Construct Used for Gene Transformation. Stem-specific Promoter: either A1 resulting in high gene expression in the mature stalk or LSG2 resulting in high gene expression in the loading sucrose section of the stalk. Vacuole leading: encoding a propeptide to guide S/ gene products to vacuole, where sucrose accumulates. Nonsilence target gene: sucrose isomerase without motifs gene silencing in plants. Multiple terminators: three recombined terminators complex to guarantee the proper termination of gene transcription. Fig. S3. PCR screening of sucrose isomerase gene in transgenic LSG2 lines. The agarose gel displayed PCR results of transgenic lines. M: DNA ladder; NC: negative control; Transgenic lines L1, L2, L3, L4, L5, L7, L9, L14, and L16 were positive of the sucrose isomerase gene; Transgenic lines $L 6, L 8, L 10, L 11, L 12$, $L 13, L 15$, and $L 17$ were negative of the sucrose isomerase gene. Fig. S4. Sugar profile of $\mathrm{T}_{1} \mathrm{~L} 9$ lines. Sugars, including isomaltulose, were measured 20-day post-anthesis in the middle section of internode 4 (counted from top). $L 9$ is one of the top lines in $T_{0}$ transgenic lines. L9-2, 9-3, 9-6, 9-7, 9-11, 9-12 are isomaltulose positive samples. Nil-L9-4, 9-8 and 9-9 are nullsegregant samples in $T_{1}$ generation. $T \times 430-1, T \times 430-2$, and $T \times 430-3$ are the non-transformed control. Fig. S5. PCR screening of sucrose isomerase gene in $T_{1}$ lines. The agarose gel displayed PCR results of transgenic lines and controls. M: $1 \mathrm{~Kb}$ DNA ladder; Positive A5 T 1 progenies: A5-2 and A5-4; Positive L2 T1 progenies: L2-1, L2-3 and L2-6; Positive L9 T, progenies: L9-2 and $L 9-4 ; T \times 430-1, T \times 430-2$ are non-transgenic control samples; PC: positive plasmid control (LSG2). Table S1. Sugar profile of controls and positive transgenic lines with isomaltulose. Table $\mathbf{S} \mathbf{2}$. Sugar profile of $\mathrm{F}_{1}$ hybrid lines of R9188 X L9.

\section{Abbreviations}

SI: Sucrose isomerase; FW: Fresh weight; NTPP: N-terminal pro-peptide; PCR: Polymerase chain reaction; qRT-PCR: Quantitative real-time PCR; HPLC: High-performance liquid chromatography; PAR: Photosynthetically active radiation; PMV: Plasma membrane vesicles; CWI: Cell wall invertase; FT: Fructosyltransferase; HPLC-ED: High-performance liquid chromatography electrochemical detection; DW: Dry weight; PMV: Plasmalemma vesicle; HEPES: N-2-hydroxyethylpiperazine-N'2-ethanesulphonic acid; EGTA: Ethyleneglycolbis (Baminoethylether)-N, N'-tetraacetic acid; DTT: Dithiothreitol; BSA: Bovine serum albumin; PVP: Polyvinylpyrrolidone; PMSF: Phenylmethyl sulphonyl fluoride; SBRB: Sorbitol-based re-suspension buffer; MES: N-morpholino ethane sulphonic acid; CCCP: Carbonyl cyanide m-chlorophenyl hydrazone.

\section{Acknowledgements}

The authors wish to acknowledge the Q-CAS (Queensland-Chinese Academy of Sciences) collaborative science fund project, with funding from the

Queensland Department of Environment and Science.

\section{Authors' contributions}

$L W, I D G, G L$, and $H J$ designed the experiments. $L W, Y P, G L, Y Z, H G$, SL, and $C D$ conducted the experiments and analyzed the data. LW, GL, and IDG wrote the manuscript. LW, IDG, and HJ supervised the project. All authors read and approved the manuscript.

\section{Funding}

This project was funded by the Queensland Department of Environment and Science.

\section{Availability of data and materials}

The datasets supporting the conclusions of this article are included in the article and its Additional files.

\section{Ethics approval and consent to participate}

Ethical approval and consent to participate are not required.

\section{Consent for publication}

All authors agree for the submission and publication of manuscript in the journal Biotechnology for Biofuel.

\section{Competing interests}

The authors declare no competing interests.

\section{Author details}

${ }^{1}$ Centre for Crop Science, Queensland Alliance for Agriculture and Food Innovation, The University of Queensland, Brisbane 4072, Queensland, Australia.

${ }^{2}$ School of Agriculture and Food Sciences, The University of Queensland, Brisbane 4072, Queensland, Australia. ${ }^{3}$ Key Laboratory of Plant Resources, Institute of Botany, Chinese Academy of Sciences, Beijing 100093, China.

Received: 22 December 2020 Accepted: 17 February 2021

Published online: 01 March 2021

\section{References}

1. Mathur S, Umakanth AV, Tonapi VA, Sharma R, Sharma MK. Sweet sorghum as biofuel feedstock: recent advances and available resources. Biotechnol Biofuels 2017; 10.

2. Holou RAY, Stevens G. Juice, sugar, and bagasse response of sweet sorghum (Sorghum bicolor (L.) Moench cv. M81E) to N fertilization and soil type. Gcb Bioenergy. 2012;4(3):302-10.

3. Soileau JM, Bradford BN. Biomass and sugar yield response of sweet sorghum to lime and fertilizer. Agron J. 1985;77(3):471-5.

4. Jackson PA. Breeding for improved sugar content in sugarcane. Field Crop Res. 2005;92(2-3):277-90.

5. Lakshmanan P, Geijskes RJ, Aitken KS, Grof CLP, Bonnett GD, Smith GR. Sugarcane biotechnology: the challenges and opportunities. Vitro Cell Dev-PI. 2005;41(4):345-63.

6. Manners JM. Functional genomics of sugarcane. Adv Bot Res. 2011:60:89-168.

7. Jiang SY, Chi YH, Wang JZ, Zhou JX, Cheng YS, Zhang BL, Ma A, Vanitha J, Ramachandran $\mathrm{S}$. Sucrose metabolism gene families and their biological functions. Sci Rep-Uk 2015; 5

8. Capell T, Christou P. Progress in plant metabolic engineering. Curr Opin Biotech. 2004;15(2): 148-54

9. Moore $\mathrm{PH}$. Temporal and spatial regulation of sucrose accumulation in the sugarcane stem. Aust J Plant Physiol. 1995;22(4):661-79.

10. Grof CPL, Campbell JA. Sugarcane sucrose metabolism: scope for molecular manipulation. Aust J Plant Physiol. 2001;28(1):1-12.

11. Bindon KA, Botha FC. Tissue discs as an experimental system for metabolic flux analysis in the sugarcane culm. S Afr J Bot. 2001;67(2):244-9.

12. Gutjahr S, Clément-Vidal A, Trouche G, Vaksmann M, Thera K, Sonderegger N, Dingkuhn M, Luquet D: Functional analysis of sugar accumulation in sorghum stems and its competition with grain filling among 
contrasted genotypes. In: Proceedings of Agro 2010 : the XIth ESA Congress. Montpellier, France. Agropolis international; 2010. p. 89-90.

13. Mathur S, Umakanth AV, Tonapi VA, Sharma R, Sharma MK. Sweet sorghum as biofuel feedstock: recent advances and available resources. Biotechnol Biofuels. 2017;10:19.

14. Stevens G, Holou RAY. Sweet sorghum as a biofuel crop. In: Halford NGKA, editor. Energy crops, vol. 3. Cambridge: Royal Society of Chemistry; 2011. p. 56-76.

15. Wu L, Birch RG. Characterization of Pantoea dispersa UQ68J: producer of a highly efficient sucrose isomerase for isomaltulose biosynthesis. J Appl Microbiol. 2004;97(1):93-103.

16. Wu LG, Birch RG. Physiological basis for enhanced sucrose accumulation in an engineered sugarcane cell line. Funct Plant Biol. 2010;37(12):1161-74.

17. Jonker D, Lina BAR, Kozianowski G. 13-week oral toxicity study with isomaltulose (Palatinose (R)) in rats. Food Chem Toxicol. 2002:40(10):1383-9.

18. Sawale PD, Shendurse AM, Mohan MS, Patil GR. Isomaltulose (Palatinose) - an emerging carbohydrate. Food Biosci. 2017;18:46-52.

19. Takazoe I. Palatinose — an isomeric alternative to sucrose. In: Grenby TH, editor. Progress in sweeteners. Barking: Elsevier; 1989. p. 143-67.

20. Lina BAR, Jonker D, Kozianowski G. Isomaltulose (Palatinose (R)): a review of biological and toxicological studies. Food Chem Toxicol. 2002;40(10):1375-81.

21. Lichtenthaler FW, Peters S. Carbohydrates as green raw materials for the chemical industry. Cr Chim. 2004;7(2):65-90.

22. Schiweck H, Munir M, Rapp KM, Schneider B, Vogel M. New developments in the use of sucrose as an industrial bulk chemical. In: Lichtenthaler FW, editor. Carbohydrates as organic raw materials. Weinheim: Wiley; 1991. p. 57-94.

23. Buchholz K, Kasche V, Bornscheuer UT. Biocatalysts and enzyme technology. Hoboken: Wiley-Blackwell; 2012

24. Wu LQ, Birch RG. Characterization of the highly efficient sucrose isomerase from Pantoea dispersa UQ68J and cloning of the sucrose isomerase gene. Appl Environ Microbiol. 2005;71(3):1581-90.

25. Loreti E, Alpi A, Perata P. Glucose and disaccharide-sensing mechanisms modulate the expression of alpha-amylase in barley embryos. Plant Physiol. 2000;123(3):939-48.

26. Sinha AK, Hofmann MG, Romer U, Kockenberger W, Elling L, Roitsch T. Metabolizable and non-metabolizable sugars activate different signal transduction pathways in tomato. Plant Physiol. 2002;128(4):1480-9.

27. Bornke F, Hajirezaei M, Heineke D, Melzer M, Herbers K, Sonnewald U. High-level production of the non-cariogenic sucrose isomer palatinose in transgenic tobacco plants strongly impairs development. Planta. 2002;214(3):356-64.

28. Bornke F, Hajirezaei M, Sonnewald U. Potato tubers as bioreactors for palatinose production. J Biotechnol. 2002;96(1):119-24.

29. Hajirezaei MR, Bornke F, Peisker M, Takahata Y, Lerchl J, Kirakosyan A, Sonnewald U. Decreased sucrose content triggers starch breakdown and respiration in stored potato tubers (Solanum tuberosum). J Exp Bot. 2003;54(382):477-88.

30. Gnanasambandam A, Birch RG. Efficient developmental mis-targeting by the sporamin NTPP vacuolar signal to plastids in young leaves of sugarcane and Arabidopsis. Plant Cell Rep. 2004;23(7):435-47.

31. Mudge SR, Basnayake SWV, Moyle RL, Osabe K, Graham MW, Morgan TE, Birch RG. Mature-stem expression of a silencing-resistant sucrose isomerase gene drives isomaltulose accumulation to high levels in sugarcane. Plant Biotechnol J. 2013;11(4):502-9.

32. Liu GQ, Godwin ID. Highly efficient sorghum transformation. Plant Cell Rep. 2012;31(6):999-1007.

33. Raghuwanshi A, Birch RG. Genetic transformation of sweet sorghum. Plant Cell Rep. 2010;29(9):997-1005.
34. Mudge SR, Osabe K, Casu RE, Bonnett GD, Manners JM, Birch RG. Efficient silencing of reporter transgenes coupled to known functional promoters in sugarcane, a highly polyploid crop species. Planta. 2009;229(3):549-58.

35. Moyle RL, Birch RG. Sugarcane Loading Stem Gene promoters drive transgene expression preferentially in the stem. Plant Mol Biol. 2013;82(1-2):51-8.

36. Bush DR, Chiou TJ, Chen LS. Molecular analysis of plant sugar and amino acid transporters. J Exp Bot. 1996;47:1205-10.

37. Bihmidine S, Baker RF, Hoffner C, Braun DM. Sucrose accumulation in sweet sorghum stems occurs by apoplasmic phloem unloading and does not involve differential Sucrose transporter expression. Bmc Plant Biol. 2015. https://doi.org/10.1186/s12870-015-0572-8.

38. Wu LG, Birch RG. Doubled sugar content in sugarcane plants modified to produce a sucrose isomer. Plant Biotechnol J. 2007:5(1):109-17.

39. Basnayake SWV, Morgan TC, Wu LG, Birch RG. Field performance of transgenic sugarcane expressing isomaltulose synthase. Plant Biotechnol J. 2012;10(2):217-25.

40. Wu LG, Birch RG. Isomaltulose is actively metabolized in plant cells. Plant Physiol. 2011;157(4):2094-101.

41. Inman-Bamber NG, Jackson PA, Hewitt M. Sucrose accumulation in sugarcane stalks does not limit photosynthesis and biomass production. Crop Pasture Sci. 2011;62(10):848-58.

42. Rolland F, Moore B, Sheen J. Sugar sensing and signaling in plants. Plant Cell. 2002;14:S185-205.

43. Fernie AR, Roessner U, Geigenberger P. The sucrose analog palatinose leads to a stimulation of sucrose degradation and starch synthesis when supplied to discs of growing potato tubers. Plant Physiol. 2001;125(4):1967-77.

44. Koch K. Sucrose metabolism: regulatory mechanisms and pivotal roles in sugar sensing and plant development. Curr Opin Plant Biol. 2004;7(3):235-46

45. Fernie AR, Geigenberger P, Stitt M. Flux an important, but neglected, component of functional glenomics. Curr Opin Plant Biol. 2005;8(2):174-82.

46. Proels RK, Huckelhoven R. Cell-wall invertases, key enzymes in the modulation of plant metabolism during defence responses. Mol Plant Pathol. 2014;15(8):858-64.

47. De Oliveira MED, Vaughan BE, Rykiel EJ. Ethanol as fuels: Energy, carbon dioxide balances, and ecological footprint. Bioscience. 2005:55(7):593-602.

48. Long HL, Li XB, Wang H, Jia JD. Biomass resources and their bioenergy potential estimation: a review. Renew Sust Energ Rev. 2013:26:344-52.

49. Liu GQ, Campbell BC, Godwin ID. Sorghum genetic transformation by particle bombardment. Methods Mol Biol. 2014;1099:219-34.

50. Liu GQ, Gilding EK, Godwin ID. A robust tissue culture system for sorghum [Sorghum bicolor (L.) Moench]. South Afr J Bot. 2015;98:157-60.

51. House LR. A guide to sorghum breeding. 2nd ed. Patancheru: International Crops Research Institute for the Semi-Arid Tropics; 1985.

52. Hugot E. Handbook of cane sugar engineering. Amsterdam: Elsevier; 1986.

53. Albertson PL, Peters KF, Grof CPL. An improved method for the measurement of cell wall invertase activity in sugarcane tissue. Aust J Plant Physiol. 2001;28(4):323-8.

\section{Publisher's Note}

Springer Nature remains neutral with regard to jurisdictional claims in published maps and institutional affiliations. 